\title{
Primitivos semánticos y modelos cognitivos en la organización del conocimiento
}

\author{
Francisco José Ruiz de Mendoza Ibáñez \\ Lorena Pérez Hernández \\ Universidad de La Rioja
}

\subsection{Resumen}

Análisis del concepto de primitivo semántico y de las diferentes metolodologías propuestas para su estudio, señaladamente las de Jackendorf y Wierzbicka. Se parte de un breve estado de la cuestión de la Semántica actual. Posteriormente se comentan algunos conceptos que han permitido ampliar el tema de los primitivos semánticos, tales como el de "dominio de referencia" formulado por Lakoff o los de "red" y "nudo" que defiende Langacker. Este último autor suscita un análisis mucho más amplio en el que se incluyen la enumeración de nuevos primitivos, denominados relacionales. Para finalizar se postula la necesidad de definir modelos genéricos de primitivos, ejemplificados a través de modelos cognitivos situacionales como los de realizar peticiones y el de control.

Palabras clave: Semántica. Primitivos semánticos. Organización del Conocimiento.

\subsection{Abstract}

Analysis of the concept of 'semantic primitive', and of the different methodologies for its study, mainly the ones proposed by Jackendorf and Wierzbicka. Firstly, a brief state of the art of modern Semantics is offered. Thereafter, some new concepts that have broadened the field of primitive semantics are explained, such as those of Lakoff's 'reference domain'or Langacker's 'network' and 'node'. This last author develops a wider analysis, in which a new category of primitives is considered, called relational primitives. Finally, the need to define new generic models of primitives is stated, exemplified throughout situational cognitive models such as those of formulating petitions and establishing control.

Keywords: Semantics. Semantic primitives. Knowledge organization. 


\section{Introducción}

La bibliografía actual sobre lo que se ha dado en llamar "semántica enciclopédica" es hoy en día impresionante. Los semantistas que trabajan en esta línea no creen ni en el análisis componencial del significado ni en la existencia de primitivos semánticos. Se alejan así no sólo del estructuralismo clásico (por ej. Nida, 1975) o de la teoría de los campos léxicos (Coseriu y Geckeler, 1981), sino incluso de otros enfoques más novedosos como los de Wierzbicka (1992, 1996, 1997) o de Jackendoff (1983, 1990, 1996ab). Según la primera, existe un metalenguaje semántico universal (compuesto de "primitivos semánticos"), basado en los significados de palabras ordinarias y susceptible de ser utilizado para la definición de cualquier pieza léxica en cualquier lengua. Para Jackendoff (1983, 1990, 1996ab), en cambio, el metalenguaje de categorías primitivas —a diferencia del de Wierzbicka - se compone de categorías abstractas.

En lingüística cognitiva, siguiendo principalmente a Lakoff (1987) y Langacker (1987), se aboga por una concepción enciclopédica del significado en la que existen sistemas de modelación del conocimiento ligados a varias formas de convencionalización que dan como resultado modelos cognitivos de varias clases:

- Esquemas de imágenes (abstracciones topológicas y preconceptuales resultado del impacto de nuestra corporeidad e interacción con el entorno en nuestra manera de entenderlo)

- Modelos metafóricos y metonímicos (proyecciones conceptuales externas e internas, respectivamente, a un dominio sobre el que se desea razonar)

- Asociaciones simbólicas de forma y sentido (construcciones)

- Modelos proposicionales o marcos (descripciones de entidades y de sus relaciones con otras en contextos estereotípicos).

La tarea de describir todos los sistemas convencionales de organización del conocimiento del mundo no es para nada liviana. Se han efectuado avances significativos en el estudio de algunos sistemas convencionales, sobre todo en la medida en que éstos se basan en metáforas y esquemas de imágenes (cf. Lakoff, 1987). En este sentido destacan, por ejemplo, los diversos trabajos de Kövecses $(1990,1995,2000)$ sobre el léxico de emociones y su fundamentación metafórica, así como el estudio de la relación entre los parámetros axiológicos y los esquemas de imágenes (Krzeszowski, 1993).

El estudio de sistemas metonímicos aún no ha recibido demasiada atención en lingüística cognitiva. Se han tratado cuestiones como la definición del concepto de metonimia (Croft, 1993; Dirven, 1993) y su clasificación (Kóvecses y Radden, 1998) y su relación con el razonamiento, la integración conceptual, la 
gramática y la adquisición de lenguas (cf. las colecciones de artículos en Panther y Radden, 1999, y Barcelona, 2000).

De manera similar, los trabajos sobre modelos cognitivos proposicionales siguen en un estadio muy programático. En Lakoff (1987) y Langacker (1987) se establecen, de forma muy provisional, algunos fundamentos para su estudio. Lakoff (1987) se ha centrado en la cuestión de la radialidad de las categorías conceptuales (cuyas extensiones metafóricas y metonímicas explotan los diversos dominios de referencia que componen una convergencia de modelos). Langacker (1987), por su parte, ha esbozado los criterios de centralidad de las caracterizaciones semánticas y ha tratado las nociones de red y nudo de acceso. Charles Fillmore es el creador e impulsor de su estudio en términos de lo que él denomina la semántica de marcos (cf. Fillmore, 1985; Fillmore y Atkins, 1992, 1994). Basándose en los principios de esta teoría, Fillmore dirige actualmente un proyecto de creación de una base de datos (FrameNet) en la que se incluye una descripción esquemática de las propiedades semánticas (roles) y sintácticas (complementos) de los predicados (cf. Lowe, Baker y Fillmore, 1997; Fillmore y Atkins, 1998).

En este trabajo es nuestra intención desarrollar los fundamentos de una teoría de la organización del conocimiento que haga explícitas las interacciones entre distintos tipos de modelo cognitivo idealizado. Utilizando conceptos de semántica relacional (cf. Evens, 1988; Chaffin, 1992), nuestro modelo desarrolla algunos aspectos de las propuestas ya existentes, en particular las de Lakoff (1987) y Langacker (1987), y es compatible, a la vez que enriquece, las propuestas sobre primitivos semánticos. Estas últimas no gozan de aceptación en lingüística cognitiva, pero nosotros creemos que tienen cabida dentro de una teoría integrada de la organización del conocimiento.

\section{Primitivos semánticos}

Tradicionalmente se considera un primitivo semántico a una unidad de significado que no se puede descomponer en otras unidades. Es el caso de los elementos causativo (causar, hacer) e incoativo (hacerse, volverse) y de verbos como limpiar y matar, analizados en los años 70 por lingüistas como James McCawley y George Lakoff. El análisis de primitivos semánticos lleva a la creación de un metalenguaje abstracto. Una versión muy sofisticada de este modo de análisis lo proporciona Jackendoff $(1983,1990)$ como parte de su semántica conceptual. Para este autor, existe en el análisis semántico un conjunto de categorías, que él denomina las "partes del habla conceptuales", tales como Cosa, Evento, Estado, Acción, Lugar, Camino, Propiedad y Cantidad. Cada constituyente sintáctico (exceptuando expletivos vacíos, como it y there) se proyecta en uno conceptual, pero no a la inversa, pues muchos componentes conceptuales se encuentran contenidos dentro de las piezas léxicas. Así, en Juan corrió hacia la

Scire. 6 : 2 (jul.-dic. 2000) 79-97. 
casa, Juan y casa corresponden a constituyentes Cosa, el sintagma prepositivo hacia la casa indica un Camino, y la oración completa es un Evento (cf. Jackendoff, 1991: 22). El componente Camino no aparece en correr, pero si en adentrarse, que además iría sujeto a un sintagma prepositivo indicativo de Lugar. Para dar una idea de cómo se aplicaría el sistema de primitivos semánticos de Jackendoff a un verbo, consideremos el caso de beber (cf. Goddard, 1998: 67):

beber $=[$ Evento CAUSAR ([Cosa]i, [Evento IR ([Cosa LÍQUIDO]j, [Camino A ([Lugar EN ([Cosa BOCA DE ([Cosa]j)])])])])]

En esta descripción beber se presenta como un evento por el que una entidad hace que entre líquido en su boca. No obstante, este tipo de descripción está sujeta a algún problema. Así, nos podemos preguntar qué diferenciaría las dos oraciones siguientes:

(1) Juan bebió todo el ron.

(2) Juan hizo que entrara todo el ron en su boca

Mientras que (1) expresa sencillamente una situación en la que Juan se bebe con normalidad el ron, (2) parece añadir un elemento de obligación que no se encuentra en (1). Sin embargo, ambas oraciones poseen una misma estructura conceptual con distintas proyecciones sintácticas.

Una versión distinta del metalenguaje de primitivos semánticos es la desarrollada por Wierzbicka (1996). Esta autora propone un sistema de expresiones procedentes del lenguaje ordinario. En la primera versión (Wierzbicka, 1972), proponía 14 primitivos semánticos. La lista inicial se ha extendido hasta incluir unos sesenta ítems actualmente (cf. Wierzbicka, 1996):

- Substantivos: yo, tú, alguien, gente/persona; algo.

- Predicados mentales: pensar, saber, querer, sentir, ver, oir.

- Habla: decir, palabra.

- Acciones, eventos, movimiento: hacer, ocurrir, mover.

- Existencia: hay.

- Vida: vivir, morir.

- Determinantes: este, el mismo, otro.

- Cuantificadores: uno, dos, algunos, todos, mucho/muchos.

- Evaluadores: bueno, malo. 
- Descriptores: grande, pequeño.

- Tiempo: cuando/tiempo, ahora, antes, después, mucho tiempo, poco tiempo, algún tiempo.

- Espacio: dónde/lugar, aquí, encima, debajo; cerca, lejos; al lado de, dentro de.

- Conectores interclausales: porque, si.

- Operadores clausales: no, puede que.

- Metapredicado: poder.

- Intensificador: muy, más.

- Taxonomía, partonomía: tipo de, parte de.

- Similitud: como.

Como ejemplo de definición basada en primitivos semánticos extraídos del lenguaje natural consideremos el de madre (siguiendo a Wierbicka, 1996: 155):

$X$ es la madre de $Y=$

- en algún momento antes de ahora, Y era muy pequeño

- en dicho momento Y estaba dentro del cuerpo de X, Y era como parte de $X$

- a causa de esto, la gente puede pensar algo así:

- X quiere hacer cosas buenas por Y

- X no quiere que le ocurran cosas malas a $Y$

En esta definición se atiende al papel biológico y psicológico de la madre. Goza de la ventaja de proporcionarnos elementos que contribuyen a la formulación de juicios de prototipicidad (al focalizar el hecho del embarazo y los consiguientes instintos maternales). Sin embargo, no da cuenta de la gran riqueza conceptual que asociamos al concepto de madre con lo que no es susceptible de explicar algunas de las extensiones metafóricas que efectuamos sobre la base de aspectos relevantes del concepto. Por ejemplo, en la definición de Wierzbicka se soslaya el papel de la madre en la concepción y creación, lo que impide explicar adecuadamente metáforas como La experiencia es la madre de la ciencia y El latín es la madre de las lenguas románicas. Por otra parte, la primera parte de la definición podría aplicarse a entidades que no fueran un hijo. Sería el caso de una mujer a la que se ha practicado un trasplante de un órgano vital, que ha nutrido y cuidado todo lo posible, pero que posteriormente ha perdido involuntariamente por un proceso de rechazo. En algún momento antes de ahora, perdido el órgano, éste llegó a ser como parte de la mujer, para luego dejar de serlo a pesar de sus precau-

Scire. $6: 2$ (jul.-dic. 2000) 79-97. 
ciones. Finalmente, en el lenguaje ordinario se pueden efectuar numerosos usos del concepto "madre" cuya impronta semántica no se puede tratar sobre la base de una definición como la de Wierzbicka. Pensemos en los siguientes ejemplos:

(3a) Madre no hay más que una.

(3b) Para un hijo, una madre lo es todo.

(3c) Soy hijo de madre soltera.

(3d) No soportaría que mi madre se vuelva a casar.

(3e) Sólo la considero mi madre porque es hija de mis abuelos.

(3f) Ese chico tiene cada uno de los genes de su madre.

Para poder interpretar el significado que se da a la palabra madre en estas oraciones, se hace necesaria una explicación más amplia del concepto, en la que se establezcan dominios de referencia. Así, (3a) y (3b) cobran sentido en el contexto de las relaciones madre-hijo, tal como se aceptan socialmente: debido a que una madre da vida, protege y cuida a sus hijos, éstos deben honrarla y respetarla haciéndola parte esencial de sus vidas. Los ejemplos (3c) y (3d) tienen como trasfondo la idea de que tradicionalmente una madre solía ser la esposa del padre. El hecho de que no se utilicen expresiones como "Es una madre casada" frente a "Es una madre soltera" nos da una idea de cómo el lenguaje recoge la tradición del modelo marital de la familia planteando las situaciones que no se atienen al mismo como excepcionales. La oración (3e) sugiere una dejación de la madre en sus deberes protectores (dar cariño, preocuparse por sus hijos, etc.). Para ello alude directamente a la mera conexión genealógica con la misma. Por fin, en (3f) se destaca el hecho de que existe una relación genética o de factores hereditarios entre madres e hijos. La similitud genética se relaciona, en la mente del hablante, con el parecido físico y de la conducta.

\section{Dominios de referencia}

Lakoff (1987) ha estudiado con cierto detalle el concepto de "madre" y sus posibles extensiones metafóricas en inglés. En la explicación de Lakoff (1987: 74), la citada categoría vendría definida no por un conjunto de condiciones necesarias y suficientes o sobre la base de unos primitivos semánticos, sino como un grupo (cluster) de modelos cognitivos idealizados que convergen: el modelo natal (la persona que da a luz es la madre), el de crianza y educación (la madre cría y educa a sus hijos), el marital (la esposa del padre es la madre), el genético (la mujer que proporciona el material genético es la madre), y el genealógico (la madre es el antepasado más cercano del sexo femenino). El grupo convergente de

Scire. $6: 2$ (jul.-dic. 2000) 79-97. 
modelos nos proporciona la subcategoría central de "madre". A éstos se añaden extensiones convencionales que representan variaciones respecto a la categoría central (por ejemplo, madre adoptiva, madre de leche, madre soltera, madre trabajadora); algunas de las variaciones se producen por vía metafórica o metonímica (por ejemplo, madre patria, lengua materna). Aunque Lakoff (1987) no aclara bien este extremo, debemos entender, en primer lugar, que cada uno de estos modelos sirve de dominio de referencia para entender ciertos aspectos del concepto de madre; es decir, el concepto de "madre" no explota todos los aspectos de los modelos convergentes de la misma forma que otros conceptos. Así, no da a luz de la misma forma una madre humana que la hembra de un animal salvaje, pues el alumbramiento humano viene asociado a un entorno asistencial hospitalario con médicos, enfermeras, material quirúrgico para posibles cesáreas, salas de espera, regalos, y otros elementos relacionados; la crianza y educación materna es diferente de la institucional; el estudio de las alteraciones genéticas por radiación explora una parte distinta del modelo genético que el del parecido entre padres e hijos; el modelo genealógico se perfila de forma distinta si se trata del trabajo de un experto en heráldica; a un jurista le conciernen aspectos del modelo marital distintos de la convivencia diaria en un mismo hogar, sujeta a reglas y acuerdos de pareja. En segundo lugar, un mismo componente de un modelo puede servir como dominio de referencia de forma distinta a dos conceptos distintos: un hospital es dominio de referencia para un médico, un celador o un administrativo como lugar de trabajo; para una madre como lugar de alumbramiento (parte, por tanto, del modelo natal).

\section{Nudos y redes}

Langacker $(1987,1990)$ ha defendido la concepción enciclopédica del lenguaje y ha esbozado algunos de los criterios que deben cumplir las caracterizaciones semánticas en el marco de dicha concepción. Para Langacker, las nociones clave son la de red y la de centralidad. En primer lugar, los conceptos son rutinas cognitivas, firmemente asentadas en nuestro sistema de conocimiento, que están interrelacionadas de forma que se facilite su coactivación, si bien mantienen suficiente autonomía como para que la ejecución de una no implique la necesaria activación del resto. Así, Langacker ve la entidad designada por una unidad simbólica como un punto de acceso a una red y su valor semántico como un conjunto de relaciones en las que participa dicho nudo. En uno de sus ejemplos, esta forma de entender la organización del conocimiento nos permitiría relacionar gato y queso sin tener que postular que el concepto de "queso" figura directamente en el de "gato". La conexión entre ambos viene dada de forma mediada por el concepto de "ratón" (el gato caza ratones y los ratones comen queso). La noción de centralidad, por su parte, depende de hasta qué punto una

Scire. $6: 2$ (jul.-dic. 2000) 79-97. 
especificación semántica es convencional, genérica, intrínseca y característica. Un aspecto del significado de un concepto es convencional en la medida en que una comunidad de hablantes lo acepta como perteneciente al mismo (por ejemplo, los gatos son animales felinos); es genérico si no constituye una forma de conocimiento anecdótica (por ej. la idea de que los gatos cazan ratones frente al conocimiento de que mi vecino es alérgico a mi gato); es intrínseco si no hace referencia a entidades externas (por ej. la forma de los objetos físicos es una propiedad intrínseca, frente al tamaño, que es relativo a otros objetos); finalmente, es característico en la medida en que sea único de la clase designada por una expresión (la forma es más característica de la clase de gatos que el color).

A nuestro juicio, la propuesta de Langacker cumple con varios requisitos importantes de cara a una teoría de la organización del conocimiento. En primer lugar, evita la conocida metáfora del "conducto" (cf. Reddy, 1979; Lakoff y Johnson, 1980), según la cual las categorías son contenedores de significado que se almacena en las mismas y que se puede transmitir mediante expresiones lingüísticas. La noción de "acceso" a una red nos permite ver la comunicación no como una transmisión de conceptos o de ideas compuestas de conceptos concatenados, sino como un proceso por el cual se dan pistas al oyente sobre qué aspectos de cada concepto resultan relevantes para la interpretación exitosa de un mensaje. Considérese la siguientes oraciones:

(4a) El buen hombre vive dedicado a su gato.

(4b) A ti te han dado gato por liebre.

(4c) Parece una gata de Angora.

(4d) Juan sólo se lava a lo gato.

(4e) Este gato no caza.

Cada una de estas oraciones efectúa un uso parcial de nuestro conocimiento sobre gatos. La oración (4a) considera al gato como animal de compañía; la (4b) como material de venta; la (4c) focaliza la idea de lujo asociada a la raza de gatos de Angora; (4d) se entiende en función de un hábito estereotipado de los gatos; (4e) alude a una característica genérica de estos animales. En nuestra propia terminología, para cada uso de los citados existe un dominio de referencia que le confiere pleno sentido. Dicho dominio se identifica por medio de claves lexicogramaticales, pero también pueden concurrir claves contextuales, en particular donde la expresión lingüística es suficientemente vaga:

(5) Utilizaremos al gato.

Scire. 6 : 2 (jul.-dic. 2000) 79-97. 
Diversos contextos pueden condicionar la activación de distintos dominios de referencia para "gato" en (5): podría tratarse de la utilidad del gato para eliminar unos ratones molestos, para servir de animal de compañía para alguien que está demasiado solo o para deshacerse de unos restos de comida, por poner algunos casos.

En segundo lugar, el hecho de que exista la posibilidad pero no el requisito de coactivación proporciona garantías de plausibilidad a la noción de red. Se accede a tantos nudos relacionados como sea necesario para los propósitos de la operación cognitiva en curso (en el uso lingüístico éstos son normalmente comunicativos), pero no a más de los imprescindibles. En este sentido, las nociones de red y nudo de acceso se adaptan a los requisitos de principios de pragmática como el de relevancia, de Sperber y Wilson (1995), para quienes el hablante busca un equilibrio óptimo entre el esfuerzo de procesamiento que se espera por parte de su interlocutor y los efectos de significado que pretende conseguir. También concuerda con el espíritu de las teorías de las redes neuronales de modelación del lenguaje. Para Lakoff y Johnson (1999, p. 498), por ejemplo, la gramática de una lengua consiste en un conjunto de conexiones neuronales, altamente estructurado, que enlazan los aspectos conceptuales y expresivos (esto incluye categorías gramaticales, estructuras gramaticales y piezas léxicas), todos ellos asentados en el sistema motosensorial. Finalmente, la visión langackeriana de la conceptualización es plenamente compatible con la teoría de los espacios mentales de Mark Turner y Gilles Fauconnier, según la que los procesos de combinación y otros modos de relación de conceptos (por ejemplo, la metafórica y metonímica) hacen sólo un uso parcial de los modelos cognitivos idealizados implicados en la tarea cognitiva de que se trate. No son los modelos completos los que se combinan o ponen en relación sino únicamente aspectos relevantes de los mismos o paquetes de conocimiento (cf. Fauconnier y Turner, 1994, 1998).

En tercer lugar, las nociones de punto de acceso y de centralidad de las caracterizaciones semánticas son compatibles con los hallazgos fundamentales de la psicología cognitiva que han propiciado la formulación de la teoría de modelos cognitivos. Nos referiremos a las características tres más importantes de los modelos cognitivos idealizados:

1) Constituyen todos estructurados ("gestalts"), en el sentido descrito por Lakoff (1987), por lo que no tienen por qué depender para su comprensión de otras categorías conceptuales con las que se relacionan; aplicando esta noción al caso del concepto de "gato", podemos percibir un gato, pensar en él, percibirlo e imaginarlo con independencia del concepto de "ratón" o incluso de algunas de sus características físicas (los bigotes, el color, el tamaño de las orejas, la longitud del rabo, etc.), si bien no de todas y, en particular, de las que Langacker denomina "intrínsecas".

Scire. $6: 2$ (jul.-dic. 2000) 79-97. 
2) Son categorías no claramente delimitadas o con límites "borrosos", que presentan grados de pertenencia a las mismas y basadas en la experiencia directa del ser humano con su entorno (Lakoff y Johnson, 1980). Una de las pruebas de la existencia de límites difusos entre categorías es que a veces se hace necesario marcar de forma explícita la pertenencia de un ítem a una categoría, como sucede por ejemplo en las siguientes oraciones: "Juan es un auténtico caballero"; "Está hecha toda una mujer"; "Está literalmente loco"; "Es claramente un águila"; "En sentido estricto, un ornitorrinco es un mamífero"; "En cierto sentido, Francia tiene forma hexagonal" (v. Taylor, 1995: 75 ss.). Siempre que guarden alguna concomitancia particularmente relevante, se hace posible incluir en una categoría entidades que no pertenecen realmente a la misma, por ejemplo: "Un tigre no es más que un gato un poco grande". Puesto que se puede acceder de modo relacional a cualquier propiedad sugerida por un entorno léxico o contextual, la estructura de redes permite la activación necesaria. Por ejemplo, para el caso de "Está hecha toda una mujer", el intensificador "toda" activa aquellos rasgos de "mujer" que forman parte de nuestro estereotipo sobre este concepto: es madura, hacendosa, trabajadora, hermosa, etc. En definitiva, son las propiedades más centrales de la categoría las que están en juego.

3) Producen efectos de prototipicidad (Lakoff, 1987, 1989). Un prototipo es el mejor ejemplo de una categoría (Rosch, 1973, 1978). Cada modelo cognitivo idealizado establece un número de propiedades. Cuanto mayor sea el grado de satisfacción de éstas por parte de un miembro de la categoría, mayor será su grado de prototipicidad. Nuestro prototipo de gato tiene, entre otros rasgos, bigotes, cola, una determinada forma del cuerpo y de las orejas (triangulares, enhiestas y puntiagudas), caza ratones y maúlla. Un gato que cumpla sólo parcialmente con estas condiciones será un peor ejemplo de la categoría que uno que las satisfaga todas. Como en el caso de la gradación de pertenencia a una categoría, los efectos de prototipicidad también se establecen en función de los criterios de centralidad. El mejor ejemplo de "gato" es el que cumple con aquellas propiedades que son convencionales, no anecdóticas o genéricas, intrínsecas y características de la clase de ítems designados por la expresión.

\section{La forma de una red relacional}

Langacker no ha hecho sino bosquejar de forma programática los principios fundamentales que guían la construcción de modelos proposicionales. Soslaya algunos problemas: 
1) La relación entre estos modelos y la estructuración del conocimiento mediante metáforas, metonimias y esquemas de imágenes. Por esta razón, no dedica espacio a cuestiones como la radialidad de las caracterizaciones y las extensiones de los conceptos.

2) La relación que existe entre la noción de dominios convergentes y la de dominio de referencia. De hecho, Langacker (1987, p. 147 ss.) sostiene que una forma lingüística sólo tiene sentido cuando se "perfila" sobre el fondo de otra estructura cognitiva: comprendemos el concepto de "lunes" en el contexto del dominio semántico de la semana de siete días; este dominio, a su vez, sólo tiene sentido con respecto a los ciclos sucesivos de días y noches. Perfilar una estructura respecto a otra no es sino utilizar la segunda como dominio de referencia para la activación parcial de nuestro conocimiento sobre la primera, con lo que esta actividad cognitiva se convierte en un factor limitador de la activación de porciones relevantes de una red.

3) La posibilidad de postular modelos cognitivos genéricos. Es cierto que Langacker entiende que los dominios que él denomina abstractos se perfilan unos sobre otros de forma sucesiva. Los dominios básicos, que son irreducibles a otros, son para él categorías como el tiempo y el espacio y quizá modelos surgidos de la experiencia sensorial tales como la temperatura, el color y el sabor. Sin embargo, la operación de perfilado de conceptos no nos lleva a modelos genéricos de por sí. Por ejemplo, el concepto de "dedo" se perfila, en una dimensión de análisis, respecto al de "mano"; éste se entiende respecto al de brazo, el cual nos lleva al de "cuerpo" (Langacker, 1987, p. 148). Finalmente, este último concepto es —en cuanto a su forma - una configuración espacial tridimensional, que constituye un concepto básico no caracterizable en función de otros. Sin embargo, podemos puntualizar, también es posible perfilar cualquiera de los dominios abstractos anteriores directamente respecto al de espacio sin necesidad de ir estableciendo una escala de perfiles y dominios de referencia. Así, el concepto de "dedo" se puede entender en no sólo en el contexto del de "mano", sino también sobre la base de dominios de referencia como el de espacio tridimensional y de otros como los de "tamaño", "forma", "peso", "materia", "instrumento", por indicar algunos relevantes. Estos son modelos genéricos, entendiendo por este término aquellos modelos que sirven de dominio de referencia a otros muchos que designan entidades fácilmente identificables e individualizables experiencialmente. Todo sustantivo de los tradicionalmente concretos se puede perfilar sobre diversos modelos genéricos, además de algunos no genéricos; sin embargo, los sustantivos que se han solido denominar abs-

Scire. $6: 2$ (jul.-dic. 2000) 79-97. 
tractos también pueden utilizar como dominios de referencia conceptos genéricos. Consideremos el caso de conceptos como "amor", "odio", "felicidad", e "ira". En su calidad de tipos de "sentimiento", este concepto cumple la función de modelo genérico en el dominio de la experiencia subjetiva. Dicha experiencia no es accesible a la observación directa, pero es deducible a partir de signos fisiológicos y conductuales específicos que forman parte de nuestro acervo epistémico (por ej. la ira produce un enrojecimiento de la piel de la cara, excesiva sudoración, determinada expresión facial e induce a ciertas formas de comportamiento agresivo).

Los modelos cognitivos genéricos se pueden definir proposicionalmente, si bien no entran en una red de relaciones semejante a la de los modelos no genéricos, cuestión a la que nos referiremos más adelante. Por el momento volvamos a la cuestión de los principios que determinan la forma de una red proposicional no genérica. Postularemos la existencia de unos primitivos semánticos relacionales susceptibles de ser parametrizados por expresiones lingüísticas no primitivas pero sí centrales, en diversos grados, para la relación establecida entre las categorías implicadas. Por ejemplo, dentro del marco de la acción, diríamos que una de las actividades típicas de los gatos es la de cazar ratones y uno de sus propósitos el de servir de animales domésticos de compañía. La actividad de cazar implica una parametrización de una actividad controlada. La función del gato como animal de compañía es instrumental en el sentido de que se ve al animal como un elemento que ayuda a conseguir determinados objetivos (no sentirse solo, estar más a gusto en el hogar).

Una acción y un instrumento son modelos cognitivos genéricos que poseen su propia estructura conceptual. La primera se puede definir como un estado de cosas en el que una entidad realiza algún tipo de actividad que se halla bajo su control y que puede tener efectos sobre otras entidades. Un instrumento, aunque es un concepto genérico, es parte del modelo de acción y se define en función de éste como una entidad que o bien facilita o bien faculta la ejecución de una acción. Dentro del mismo marco de la acción se pueden distinguir también un resultado necesario o un resultado típico, así como un agente, un paciente y una causa. Todos estos elementos del marco de acción configuran tipos relacionales primitivos que se pueden parametrizar dando como resultado conjuntos de relaciones específicas aplicables a distintas entidades, con diversos grados de centralidad y sus consiguientes efectos de prototipicidad. La instanciación de un tipo relacional y su consiguiente aplicación a una o más entidades produce una proposición no genérica que forma una red. La

Scire. $6: 2$ (jul.-dic. 2000) 79-97. 
relación agentiva, por ejemplo, relaciona "gato" con "ratón" mediante el predicado "caza" y a este último con "queso" mediante el predicado "come". Estas dos activaciones se producen en función de dos dominios de referencia distintos: uno, el de las actividades de los gatos como animales de presa; otro, el de los hábitos alimenticios de los roedores.

A modo de resumen sucinto, proporcionamos seguidamente un listado de tipos de relación (o primitivos relacionales) más una breve descripción de los mismos:

- Agentivo: una entidad realiza una actividad controlada (por ej. el carpintero trabaja la madera).

- Factitivo: como resultado de una actividad controlada surge otra entidad (por ej. un zapatero hace zapatos).

- Instrumental: una entidad se utiliza para facilitar o posibilitar la realización de una actividad controlada (por ej. el carpintero corta la madera con una sierra).

- Causativo: una entidad es responsable de que ocurra un determinado evento o de que se de un estado de cosas (por ej. el calor dilata el hierro).

- Resultativo: una entidad es el resultado necesario de una actividad controlada o no controlada (por ej. si se hace arder madera o arde sola, ésta se reduce a cenizas).

- Procesual: una entidad se ve implicada en una actividad sobre la que no tiene control (por ej. el corazón late).

- Originatorio: una entidad se convierte en otra relacionada con la primera (por ej. el agua se convierte en hielo).

- Posicionador: una entidad se relaciona con otra y depende de una de las dos entidades que la relación se mantenga (por ej. un esposo tiene una esposa).

- Material: una entidad constituye el material del que está hecha otra entidad (por ej. una mesa puede estar hecha de madera, plástico, mármol, etc.).

- Contenedor: una entidad se percibe de forma que contiene o incluye a otra, bien necesariamente o de manera acostumbrada (por ej. el mar tiene agua; una casa tiene habitaciones).

- Partitivo: una entidad se describe de forma que consta de otras entidades (por ej. una mesa tiene tablero y patas).

- Locativo: una entidad se suele asociar a determinada localización (por ej. se encuentra un conejo en su madriguera). 
- Atributivo: a una entidad se le adscribe una propiedad típica o necesaria (por ej. el diamante es duro; la goma es elástica; un elefante es grande).

Podemos dar un ejemplo muy sencillo de cómo algunos de estos primitivos relacionales se parametrizan en una expresión lingüística. Consideremos la siguiente oración:

(6) La mesa de roble que encargamos al carpintero todavía no está acaba$d a$, pero podemos utilizar mientras tanto la que tenemos guardada en el trastero.

Por una parte, existe una relación factitiva entre "carpintero" y "mesa", una relación material entre "mesa" y "roble", y una relación locativa entre "mesa" y "trastero". Por otra parte, encargar la mesa al carpintero y utilizar otra constituyen parametrizaciones de dos actividades controladas (relación agentiva).

\section{Modelos cognitivos genéricos, esquemas de imágenes y mode- los situacionales}

Como señalábamos más arriba, un modelo genérico se define también proposicionalmente. Sin embargo no se aplica a entidades concretas sino a otros conceptos de índole genérica. La descripción de cada uno de los primitivos relacionales que hemos proporcionado en el apartado anterior hace uso de nociones genéricas tales como "actividad", "proceso", "relación", "entidad", "control", "acción", "evento", "localización", "material", "parte", e "inclusión". Todas estas nociones surgen de la capacidad de generalización del ser humano y forman parte de su conocimiento del mundo. Hemos definido más arriba el concepto de "acción" como una actividad controlada. Quizá es posible definir el propio concepto de "actividad" sencillamente como "lo que una entidad hace de forma controlada". Un "proceso" sería una actividad no controlada. Un "evento" es sencillamente "una acción o proceso que ocurre". "Material" es aquella sustancia de la que está hecha una entidad. "Localización" es la posición relativa de un entidad respecto a otras. "Inclusión" es una forma de localización en la que una de las entidades contiene o encierra a la otra. "Parte" es una relación estructural en la que una entidad se percibe como separable en otras. Finalmente, "control" es una forma de determinar la conducta de una o varias entidades o estados de cosas (situaciones, eventos).

Algunos de estos modelos genéricos poseen estructura topológica, es decir, tienen un correlato como esquemas de imágenes. Es el caso claro de "localización", "parte" e "inclusión", para los que existen configuraciones espaciales esquemáticas. Los otros modelos genéricos son puramente proposicionales pero 
la comprensión de algunos se asienta comúnmente en esquemas de imágenes. Por ejemplo, una "acción" tiene normalmente un objetivo que se entiende como el destino del esquema de camino (por ej. Así avanzamos hacia nuestra perdición). La acción en sí misma se comprende como una forma de movimiento hacia el destino (esto es lo que Talmy (1985), ha estudiado como parte de la "dinámica de la fuerza"). Lo mismo se aplica a la noción de "proceso" cuyo resultado es también el final de un camino (por ej. Ha llegado a ser un buen abogado). En otros casos, la base topológica resulta algo menos evidente a primera vista, pero eso no significa que no exista en cierto sentido. Así, el concepto de "entidad" incluye el de "objeto" que se entiende en función del dominio básico del espacio tridimensional. Incluso el concepto de "control" mantiene relación con un esquema de imagen en cuanto desarrollamos mínimamente su estructura lógica. Consideremos la expresión siguiente:

En esta oración se expresa cómo una persona ha perdido el control sobre sí misma. Para ello recurre a lo que Lakoff (1996) ha denominado la metáfora de la "persona dividida", según la cual una persona consta de un "sujeto" (o conciencia experimentadora) y de un "yo" (que representa sus aspectos corporales y funcionales). Para poder apreciar todo el valor significativo de (7) debemos ir, no obstante, un poco más lejos. La metáfora de la persona dividida sólo nos indica que hay en juego dos aspectos de la persona. Necesitamos saber cómo estar "fuera" de uno mismo metafóricamente implica pérdida de control. Para ello recurrimos a la siguiente descripción del modelo cognitivo de control:

\section{(7) Juan está fuera de sí.}

Es obvio que (7) presenta una situación indeseable en la que el sujeto racional de Juan ha perdido control sobre su yo funcional debido a la presencia figurada de un impedimento físico (el sujeto está fuera del yo), situación que no es deseable. El esquema de imagen que ayuda a parametrizar el concepto de "barrera física" es el de "contenedor".

Finalmente, dedicaremos unas líneas a lo que podemos denominar modelos cognitivos situacionales. Nos referimos en principio a modelos como los conocidos "guiones" de Schank y Abelson (1977), que describían secuencias estereotipadas de acciones, tales como las de entrar en un restaurante, llamar al camarero, solicitar el menú, pedir la comida, comer, pagar e irse. Existen, a nuestro juicio, modelos cognitivos situacionales más genéricos, como el que determina las condiciones de satisfacción de los distintos actos de habla (como las formuladas en su tiempo por Searle, 1975). Así, para que ciertas expresiones lingüísticas se 
entiendan como peticiones, debemos disponer de un contexto en el que se den al menos las siguientes condiciones (modelo cognitivo genérico de petición):

(a) Al hablante le es manifiesto que el estado de cosas designado por la expresión lingüística resulta beneficioso para el hablante (o para una tercera persona sobre la que el hablan te quiere que recaiga el beneficio) y costoso para el oyente.

(b) Al hablante le es manifiesto que el oyente tiene capacidad para hacer que tenga lugar el estado de cosas designado por la expresión lingüística.

(c) El hablante desea que tenga lugar el estado de cosas designado por la expresión lingüistica.

(d) El hablante deja cierto grado de libertad para que el oyente se niegue a hacer que tenga lugar el estado de cosas designado por la predicación.

Expresiones como las que consignamos en (8) activan claramente este modelo:

(8a) ¿Quieres abrir la ventana?

(8b) ¿Te importaría ayudarme un momento?

(8c) ¿Puedes acercarte un poco más?

(8d) No te arrimes a la pintura fresca, te lo ruego.

(8e) Hace demasiado frío aquí.

En conclusión, un modelo situacional genérico extrae condiciones genéricas que se aplican a numerosas situaciones particulares y puede describirse en términos proposicionales. Otro ejemplo de modelo es el que establece un contexto de control (modelo cognitivo genérico de control):

(a) Una entidad controla una entidad o un conjunto de entidades cuando la primera puede determinar la conducta de la segunda o segundas.

(b) Una entidad controla un estado de cosas cuando puede determinar la existencia de dicho estado de cosas.

(c) El control de una entidad sobre otras o sobre un estado de cosas aumenta o disminuye de acuerdo con la ausencia o presencia respectivamente de barreras físicas entre la entidad controladora y las demás (en este sentido la distancia se puede entender como una barrera física). 
(d) El control máximo de una entidad, conjunto de entidades o estado de cosas es normalmente deseable. El control mínimo o la ausencia de control no es normalmente deseable.

\section{Conclusión}

En este trabajo hemos podido desarrollar algunos aspectos de la teoría de los modelos cognitivos combinando las nociones de red, acceso y centralidad con las de dominio de referencia y grado de generalización de las caracterizaciones. Hemos propuesto una tipología de primitivos relacionales cuya diferencia fundamental respecto a otras clasificaciones de primitivos semánticos reside en que en nuestra versión un primitivo no es tanto un átomo de significado como un concepto genérico susceptible de ser instanciado o parametrizado de acuerdo con los criterios de centralidad que Langacker ha establecido para las especificaciones semánticas. Asimismo, hemos examinado la relevancia de postular modelos cognitivos genéricos para una teoría de la organización del conocimiento. Para estos modelos se pueden crear descripciones proposicionales, si bien no parecen obedecer al formato de red relacional por estar a la base de la propia tipología de relaciones primitivas y no ser instanciables.

\section{Bibliografía}

Barcelona, A., (2000). Metaphor and Metonymy at the Crossroads. Berlin, New York : Mouton de Gruyter, 2000.

Chaffin, R. (1992). The concept of semantic relation // Lehrer, A. ; Kittay, E. F. (eds.). Frames, Fields, and Contrasts. Hillsdale, N.J. : Lawrence Erlbaum, 1992.

Coseriu, E. ; Geckeler, H. (1981). Trends in Structural Semantics. Tübingen : Gunter Narr, 1981.

Croft, W. (1993). The role of domains in the interpretation of metaphors and metonymies. Cognitive Linguistics. 4 : 4 (1993) 335-370.

Dirven, R. (1993). Metonymy and metaphor : different mental strategies of conceptualisation. Leuvense Bijdragen. 82 (1993). 1-25.

Evens, M. W. (ed.). (1988). Relational Models of the Lexicon. Representing Knowledge in Semantic Networks. Cambridge : Cambridge University Press, 1988.

Fauconnier, G. ; Turner, M. (1994). Conceptual projection and middle spaces. UCSD : Department of Cognitive Science. San Diego, 1994.

Fauconnier, G. ; Turner, M. (1998). Principles of conceptual integration. // Koenig, J.P. (ed.). Discourse and Cognition : Bridging the Gap. Stanford : CSLI Publication, 1998.

Fillmore, C. ; Atkins, B. T. S. (1992). Towards a frame-based lexicon : the semantics of RISK and its neighbours. // Lehrer, A. ; Kittay, E. (eds.). Frames, Fields and Contrasts. Hillsdale, NJ. : Lawrence Erlbaum, 1992.

Scire. $6: 2$ (jul.-dic. 2000) 79-97. 
Fillmore, C. ; Atkins, B. T. S. (1994). Starting where dictionaries stop : the challenge of corpus lexicography.// Atkins, B. T. S. ; Zampolli, A. (eds.). Computational Approaches to the Lexicon. Oxford : Oxford University Press, 1994.

Fillmore, J. Charles ; Atkins, B. T. S. (1998). FrameNet and lexicographic relevance. // Proceedings of the First International Conference on Language Resources and Evaluation; Granada, Spain, 1998.

Fillmore, C. J. (1985). Frames and the semantics of understanding. // Quaderni di Semantica. $6: 2$ (1985) 222-253.

Goddard, C. (1998). Semantic Analysis: A Practical Introduction. Oxford : Oxford University Press, 1998.

Jackendoff, R. (1983). Semantics and Cognition. Cambridge, Mass : MIT Press, 1983.

Jackendoff, R. (1990). Semantic Structures. Cambridge, Mass : MIT Press, 1990.

Jackendoff, R. (1996a). Semantics and cognition. // Lappin, S. (ed.). The Handbook of Contemporary Semantics Theory. Oxford : Basil Blackwell, 1996.

Jackendoff, R. (1996b). Conceptual semantics and cognitive linguistics. Cognitive Linguistics. 7 (1996) 93-129.

Kövecses, Z. and Radden, G. (1998). Metonymy : developing a cognitive linguistic view.// Cognitive Linguistics. 9 : 1 (1998) 37-77.

Kövecses, Z. (1990). Emotion Concepts. U.S.A. : Springer-Verlag, 1990.

Kövecses, Z. (1991). Happiness : a definitional effort // Metaphor and Symbolic Activity. $6: 1$ (1991). 29-46, .

Kövecses, Z. (1995). Language and emotion concepts. // Russell, J.A.; Fernández-Dols, J.M.; Manstead, A. S. R. ;Wellenkamp, J. C. (eds.). Everyday Conceptions of Emotion : An Introduction to the Psychology, Anthropology, and Linguistics of Emotion. Dordrecht : Kluwer, 1995.

Kovecses, Z. (2000). Metaphor and emotion : language, culture, and body in human feeling. Cambridge : Cambridge University Press, 2000.

Krzeszowski, T. P. (1993). The axiological parameter in preconceptional image schemata. // Geiger, R.A. ; Rudzka-Ostyn, B. (eds.). Conceptualizations and Mental Processing in Language. Berlin ; New York : Mouton de Gruyter, 1993.

Lakoff, G. ; Johnson, M. (1980). Metaphors We Live By. Chicago y Londres : The University of Chicago Press, 1980.

Lakoff, G. ; Johnson, M. (1999). Philosophy in the Flesh. Chicago : University of Chicago Press, 1999.

Lakoff, G. (1987). Women, Fire, and Dangerous Tings : What Categories Reveal about the Minds. Chicago y Londres : The University of Chicago Press, 1987.

Lakoff, G. (1989). Some empirical results about the nature of concepts. // Mind and Language. 4 : 1-2 (1989) 103-129.

Lakoff, G. (1990). The Invariance Hypothesis : is abstract reason based on image-schemas?. // Cognitive Linguistics. 1 : 1 (1990). 39-74. 
Lakoff, G. (1996). Sorry, I"m not myself today : the metaphor system for conceptualizing the self. // Fauconnier, G. and Sweetser, E. (eds.). Spaces, Worlds and Grammar. Chicago : Chicago University Press, 1996.

Langacker, R. W. (1987). Foundations of Cognitive Grammar : Vol I : Theoretical Prerequisites. Stanford, Cal. : Stanford University Press, 1987.

Langacker, R. W. (1990). Concept, Image, and Symbol : The Cognitive Basis of Grammar. Berlin, New York : Mouton de Gruyter, 1990.

Lowe, J.B. ; Baker, C.F. ; Fillmore, C.J. (1997). A frame-semantic approach to semantic annotation. // Proceedings of the SIGLEX workshopTagging Text with Lexical Semantics : Why, What, and How? : Held April4-5, in Washington, D.C., USA in conjunction with ANLP-97.

Nida, E. A. (1975). Componential Analysis of Meaning. The Hague : Mouton, 1975.

Panther, K-U. ; Radden, G., 1999 (eds.). Metonymy in Language and Thought. Amsterdam, Philadelphia : John Benjamins, 1999.

Reddy, M. (1979). The conduit metaphor. // Ortony, A. (ed.), Metaphor and Thought. Cambridge : CUP, 1979. P. 284-324, .

Schank, R. C. ; Abelson, R. P. (1977). Scripts, Plans, Goals and Understanding. Hillsdale, NJ : Lawrence Erlbaum, 1977.

Searle, J.R. (1975). Indirect speech acts, // Cole, P. ; J. L. Morgan (eds.). Syntax and Semantics : Vol. 3 : Speech Acts. New York : Academic Press, 1975.

Sperber, D. : Wilson, D. (1995). Relevance, Communication and Cognition. 2nd ed. Oxford and New York : Blackwell, 1995.

Talmy, L. (1985). Lexicalization patterns : semantic structure in lexical forms. // Shopen, T. (ed.). Language Typology and Syntactic Description : vol. 3. Cambridge : Cambridge University Press, 1985.

Taylor, (1995). Linguistic Categorization : Prototypes in Linguistic Theory. Oxford : Clarendon Press. 2nd ed. 1995.

Wierzbicka, A. (1972). Semantic Primitives. Frankfurt am Main : Athenäum, 1972.

Wierzbicka, A. (1992). Semantics, Culture, and Cognition. Oxford : Oxford University Press, 1992.

Wierzbicka, A. (1997). Semantics. Primes and Universals. Oxford ; New York : Oxford University Press, 1997.

Wierzbicka, A. (1997). Understanding Cultures through their Keywords. Oxford : Oxford University Press, 1997. 